\title{
The Cytology, Isozyme, HPLC Fingerprint, and Interspecific Hybridization Studies of Genus Epimedium (Berberidaceae)
}

\author{
Lin-Jiao Wang ${ }^{1}$ and Mao-Yin Sheng ${ }^{2,3,4}$ \\ ${ }^{1}$ School of Vocation and Technology, Guizhou Normal University, Guiyang, Guizhou 550001, China \\ ${ }^{2}$ Institute of South China Karst, Guizhou Normal University, Guiyang 550001, China \\ ${ }^{3}$ State Key Laboratory Incubation Base for Karst Mountain Ecology Environment of Guizhou Province, Guiyang 550001, China \\ ${ }^{4}$ School of Life Science, Nanjing University, Nanjing, Jiangsu 210093, China
}

Correspondence should be addressed to Mao-Yin Sheng; shmoy@163.com

Received 23 May 2013; Accepted 1 August 2013

Academic Editors: G. Biala, G. M. Campo, R. Fantozzi, and D. K. Miller

\begin{abstract}
Copyright (C) 2013 L.-J. Wang and M.-Y. Sheng. This is an open access article distributed under the Creative Commons Attribution License, which permits unrestricted use, distribution, and reproduction in any medium, provided the original work is properly cited.
\end{abstract}

\begin{abstract}
104 samples from 27 accessions belonging to 12 species of genus Epimedium were studied on the basis of cytology observation, POD (i.e., peroxide) isozyme, high performance liquid chromatography (i.e., HPLC) fingerprint, and interspecific hybridization. The cytology observation showed karyotypes of twelve species studied; all are 2A symmetry type of Stebbins standard and similar to each other, and except for karyotype of E. leptorrhizum which is $2 \mathrm{n}=2 \mathrm{x}=8 \mathrm{~m}(2 \mathrm{SAT})+4 \mathrm{sm}$, the rest are $2 \mathrm{n}=2 \mathrm{x}=6 \mathrm{~m}(2 \mathrm{SAT})+6 \mathrm{sm}$. Chromosomes C-banding of barrenwort species varies, with 15 to 22 bands, consisting of centromeric bands, intercalary bands, terminal bands, and middle satellite bands. Results of POD isozyme showed that the zymographs vary greatly and sixteen bands were detected in the eleven species, and each species has its own characteristic bands different from the others. Studies on the HPLC fingerprint showed that the HPLC fingerprint of different species has characteristic peaks, divided into two regions (retention time $<10 \mathrm{~min}$ and retention time $>10 \mathrm{~min}$ ). Results of interspecific hybridization showed that crosses of any combination among seven species studied are successful and the rates of grain set vary greatly. Based on these results, the system and phylogeny of this genus were inferred.
\end{abstract}

\section{Introduction}

Barrenwort (Epimedium, Berberidaceae) is a traditional Chinese medicine named as Yinyanghuo, Xianlinpi, and Yangheye in China [1-3]. The plant is effective in strengthening kidneys and curing rheumatism, widely used in the treatment of osteoporosis, hypertension, coronary heart disease [4], caducity, cancer, and so on [1-3]. Many flavonol glycosides have been isolated from a number of Epimedium plants, though the relation between these flavonol glycosides and the pharmacological activities of the drug is still obscure [4]. In Japan, Europe, and America, barrenwort are also very popular as graceful garden plants.

Epimedium is a genus of the Old World. Members disperse from Japan to Algeria and mainly occur in eastern Asia and the Mediterranean lands [5]. Approximately $80 \%$ of the total species are found in central-southeastern China [6]. Linnaeus recorded this genus and its type species E. alpinum in 1753. After that, Morren and Decaisne (1834); Franchet (1886); Komarov (1908); and Stearn $(1938,2002)$ made monographic and systematic study of Epimedium, respectively. Up till now, more than 60 species of Epimedium are recognized. Stearn [5, 7] established the most comprehensive classification system of this genus. In his monograph, he arranged the genus into two subgenera, Epimedium L. and Rhizophyllum (Fischer \& Meyer) Stearn, mainly based on whether the flowering stem has leaves or not, and he divided the subgenus, Epimedium, into four sections mainly according to their geographical distribution and infrageneric relationship. Among the four sections, members of section Diphyllon (Kom.) Stearn were all endemic to China and subdivided into four series: Campanulatae Stearn, Davidianae Stearn, Dolichocerae Stearn, 
and Brachycerae Stearn based on corolla characteristics such as petal type, the form and relative size of the inner sepals and petals, and flower dimension.

Up to now, lots of works have been adopted to deduce the system and evolution of this genus such as pollen morphology $[8,9]$, cytology $[10,11]$, isozyme [12], molecular biology [13$16]$, biogeography $[6,17]$, chemical classification $[4,12,18]$, and so on. Results showed that the infrageneric classification was generally consistent with its phytogeographic distribution, and the phylogenetic relationship among sections was basically clear in Epimedium. However, for lots of Epimedium species with multifarious petals are nested together in China and the petal evolved is quite controversial, the system of Chinese species is still not revealed well [18]. Recently, many further researches were performed for the system and phylogeny of Epimedium [17, 19, 20]. As an intractable genus in taxonomy, however, there still remain several problems about the classification and phylogenetic relationship of Epimedium species, especially for the Chinese Epimedium species. As a result, it is essential to establish a natural arrangement of Epimedium.

In this paper, 104 samples from 27 accessions belonging to twelve barrenwort species were systemically studied on the cytology, peroxide (POD) isozyme, high performance liquid chromatography (HPLC) fingerprint, and interspecific hybridization to infer the system and phylogeny of this genus.

\section{Materials and Methods}

2.1. Plant Materials. We collected 104 samples from 27 accessions belonging to twelve barrenwort species (Table 1) and planted them in pots filled with compost (one plant per pot). All the pots were kept in greenhouses at the Institute of Plant Genetics and Breeding (IPGB) under identical conditions. The entire study was carried out at the same institute.

2.2. Karyotype Analyses. Somatic chromosomes were studied in root meristems of individuals which were pretreated in $\alpha$-bromine naphthalin at $23^{\circ} \mathrm{C}$ for $5 \mathrm{~h}$, then fixed in ethanol:acetic acid $(3: 1)$ for $4 \sim 12 \mathrm{~h}$, and stored in $70 \%$ aqueous ethanol. Root tips were stained according to Feulgen technique, meristems were macerated in $1 \mathrm{~mol} / \mathrm{L}$ hydrochloric acid at $60^{\circ} \mathrm{C}$ for 10 minutes before squashing, and slides were made permanent using Balata as the mounting medium. At least 10 metaphases were drawn for each population using an Olympus BX51 camera (Olympus, Japan), selecting the five best for measurements. The nomenclature used for the description of the chromosome morphology is that proposed by Levan et al. [21].

For the numerical characterization of the karyotypes, the following parameters were calculated: (1) total chromosome length of the haploid complement (TCL); (2) mean chromosome length (CL); (3) mean centromere index (CI); (4) intrachromosomal asymmetry index $\left(A_{1}\right)=1-\left[\sum(b / B) / n\right]$; and (5) interchromosomal asymmetry index $\left(A_{2}\right)=s / x$, where $b$ and $B$ are the mean length of short and long arms of each pair of homologues, respectively, $n$ is the number of homologues, $s$ is the standard deviation, and $x$ is the mean chromosome length. Karyotype asymmetry has been determined using the categories of Stebbins [22].

2.3. Giemsa C-Band Analyses. Somatic chromosomes were studied in root meristems of individuals which were pretreated in $0.2 \%$ aqueous colchicine at $23^{\circ} \mathrm{C}$ for $4 \mathrm{~h}$, then fixed in ethanol:acetic acid $(3: 1)$ for $24 \mathrm{~h}$, and stored in $70 \%$ aqueous ethanol; meristems were squashed in $45 \%$ acetum. Cover glasses were uncovered after freezing, and then samples were set in air at $23^{\circ} \mathrm{C}$ for five days before being treated by Giemsa chromosome banding. The improved BSG method of chromosome C-banding was used. Mature samples were treated in $0.2 \mathrm{~mol} / \mathrm{L}$ hydrochloric acid for 50 minutes, treated in $50 \%$ aqueous $\mathrm{Ba}(\mathrm{OH})_{2}$ at $60^{\circ} \mathrm{C}$ for 30 minutes after being washed by water, then treated in $2 \times$ SSC solution at $60^{\circ} \mathrm{C}$ for $5 \mathrm{~h}$ after being washed by water, and finally dyed in 3\% aqueous Giemsa ( $\mathrm{pH} 6.8$ ) for $1 \mathrm{~h}$. Chromosomes C-bandings among species were compared by the method of Li [23].

2.4. PAGE Analyses of POD Isozyme. The polyacrylamide gel electrophoresis (PAGE) method of POD isozyme analyses was described by Hu and Wang [24]. The POD was extracted from tender, 2-week-old leaves. The parameters of bio-gel for separation were as follows: $T$ (total concentration of Acr and $\mathrm{Bis}$ ) $=7.5 \%$ and $C$ (the rate of $\mathrm{B}$ is in $T$ ) $=2.6 \%$. $R f$ value $=$ moving length of the band/moving length of the front line. The coefficient $(c)$ and dissimilarity coefficient $(d)$ of zymogram were used to analyse the relation among species. $c=(2 w /(a+b)) \times 100 \%$, where $a=$ the number of zymogram bands of species A, $b=$ the number of zymogram bands of species $\mathrm{B}$, and $w=$ the number of zymogram bands common to species $\mathrm{A}$ and $\mathrm{B}$, and $d=100 \%-c$. Idiograms were drawn based on the results and analyzed.

2.5. HPLC Fingerprint of Flavonoids. The HPLC fingerprints were estimated by following the method described by CCP [25]. The HPLC system consisted of an LC2010 and CLASSVP Ver6.12 computer system (all components from Shimadzu, Kyoto, Japan). A reversed-phase $\mathrm{C}_{18}$ (YMC, Japan) column $(150 \times 4.6 \mathrm{~mm})$ was used for separation. The mobile phase consisted of acetonitrile and water $(25: 75)$. The flow rate was kept constant at $1.0 \mathrm{~mL} / \mathrm{min}$ at room temperature $\left(30^{\circ} \mathrm{C}\right)$. The detection was performed at $270 \mathrm{~nm}$ using an SPD-M10A VP photodiode array detector. The samples delivered into the system, one at a time, measured $10 \mu \mathrm{L}$ each. All the samples used in the study were from mature leaves.

2.6. Interspecific Hybridization. Seven species, E. myrianthum, E. acuminatum, E. wushanense, E. letorrhizum, E. luodianense, E. simplicifolium, and E. yinjiangense grown in green house, were selected as female and male parents, crossed with each other. As flowers opened (before anther dehiscence), the species chosen as female parents were emasculated and pollinated by rubbing them with newly dehisced anthers of the male parents. More than 200 flowers were pollinated per cross. Remaining buds in the inflorescences were removed. Twenty days later, the rate of grain set $(\%)=$ 
TABle 1: Epimedium accessions used in this study.

\begin{tabular}{|c|c|c|c|c|c|}
\hline Accessions & Species & Native to & Symbols & Speciman no. & Size of flower \\
\hline EP04100701AC & E. acuminatum Franch & Guizhou, Guiyang, China & $\mathrm{ACl}$ & 04100701 & Large \\
\hline EP05050709AC & E. acuminatum Franch & Guizhou, Yanhe, China & AC2 & 05050709 & Large \\
\hline EP05101001AC & E. acuminatum Franch & Guizhou, Mentan, China & AC3 & 05101001 & Large \\
\hline EP05101002AC & E. acuminatum Franch & Yunnan, Kunming, China & AC4 & 05101002 & Large \\
\hline EP05050801AC & E. acuminatum Franch & Guizhou, Dejiang, China & AC5 & 05050801 & Large \\
\hline EP05021002YI & E. yinjiangense M. Y. Sheng and Q. F. Chen & Guizhou, Yinjiang, China & YI1 & 05021002 & Large \\
\hline EP05021003YI & E. yinjiangense M. Y. Sheng and Q. F. Chen & Guizhou, Yinjiang, China & YI2 & 05021003 & Large \\
\hline EP05050403LU & E. luodianense M. Y. Sheng and Q. F. Chen & Guizhou, Luodian, China & LU1 & 05050403 & Large \\
\hline EP04120001LU & E. luodianense M. Y. Sheng and Q. F. Chen & Guizhou, Pingtan, China & LU2 & 04200001 & Large \\
\hline EP04081205SI & E. simplicifolium T. S. Ying & Guizhou, Yanhe, China & SI1 & 04081205 & Large \\
\hline EP04081208SI & E. simplicifolium T. S. Ying & Guizhou, Yanhe, China & SI2 & 04081208 & Large \\
\hline EP06012301FR & E. franchetii Stearn & Guizhou, Tongren, China & FR & 06012301 & Large \\
\hline EP04041001WU & E. wushanense T. S. Ying & Guizhou, Kaili, China & WU1 & 04041001 & Large \\
\hline EP05051102WU & E. wushanense T. S. Ying & Guizhou vivariuam, China & WU2 & 05051102 & Large \\
\hline EP05032101WU & E. wushanense T. S. Ying & Guizhou, Guiyang, China & WU3 & 05032101 & Large \\
\hline EP04061505LE & E. leptorrhizum Stearn & Guizhou, Dejiang, China & LE1 & 04061505 & Large \\
\hline EP04091201LE & E. leptorrhizum Stearn & Guizhou, Wuchuan, China & LE2 & 04091201 & Large \\
\hline EP04061501LE & E. leptorrhizum Stearn & Guizhou, Yinjiang. China & LE3 & 04061501 & Large \\
\hline EP04052201LE & E. leptorrhizum Stearn & Guizhou, Guiyang, China & LE4 & 04052201 & Large \\
\hline EP05100801DA & E. davidii Franch & Yunnan, Kunming, China & DA & 05101001 & Large \\
\hline EP04072202AL & E. alpinum L. & Munich, German & AL1 & 04072201 & Large \\
\hline EP04072201AL & E. alpinum L. & Munich vivariuam, German & AL2 & 04072201 & Large \\
\hline EP05092302PU & E. pubigerum (DC.) Morren and Decne. & Munich, German & PU1 & 05092302 & Large \\
\hline EP05092301PU & E. pubigerum (DC.) Morren and Decne. & Munich vivariuam, German & PU2 & 05092301 & Large \\
\hline EP03100202SA & E. sagittatum (Sieb. et. Zucc.) Maxim. & Guizhou vivarium, China & SA1 & 03100202 & Small \\
\hline EP03100201SA & E. sagittatum (Sieb. et. Zucc.) Maxim. & Guizhou Shibing, China & SA2 & 03100201 & Small \\
\hline EP04050401MY & E. myrianthum Stearn & Guizhou, Shibing, China & MY & 04050401 & Small \\
\hline
\end{tabular}

(the number of grain set/the number of pollinated flowers) $\times 100$. Based on the rate of grain set, the relations of these seven species were compared by the hierarchical cluster of SPSS [26].

\section{Results}

3.1. Morphological Observation and Karyotype Analyses of Chromosomes. Based on the size of flower, twelve species can be grouped into two types, type one is small flower including E. sagittatum and E. myrianthum, type two is large flower, the rest. The results of chromosomal observations of twelve species showed all species studied were diploid $(2 \mathrm{n}=2 \mathrm{x}=12)$ and had one pair of middle satellite chromosomes. Expect for the middle satellite chromosomes of E. leptorrhizum, E. simplicifolium and E. wushanense are in short arms of no. 2 chromosomes; the rest are no. 1 chromosomes. Tetraploid cells sporadically were found in E. letorrhizum root meristems among twelve species. The total length of haploid complement (TCL) of E. yinjiangense and E. alpinum are obviously small, $29.23 \pm 2.36 \mu \mathrm{m}$ and $32.96 \pm 1.34 \mu \mathrm{m}$, respectively. And the range of chromosome length of E. yinjiangense is $2.15 \sim 2.92 \mu \mathrm{m}$ and E. alpinum 2.22 $3.06 \mu \mathrm{m}$.
The parameters (Table 2), figures (Figure 1), and karyotypes (Figure 2) of twelve species metaphase chromosomes were studied. The results showed that their karyotypes are similar to each other, only including $\mathrm{m}$ and sm two types chromosome. Twelve species karyotypes are all 2A type of Stebbin's asymmetry categories. Among them, the karyotype formulas of E. sagittatum, E. myrianthum, E. acuminatun, E. wushanense, E. simplicifolium, E. yinjianense, E. luodianense, E. davidii, E. pubigerum, E. franchetii, and E. alpinum are $2 \mathrm{n}=$ $2 \mathrm{x}=6 \mathrm{~m}(2 \mathrm{SAT})+6 \mathrm{sm}$, and E. leptorrhizum is $2 \mathrm{n}=2 \mathrm{x}=8 \mathrm{~m}$ $(2 \mathrm{SAT})+4 \mathrm{sm}$.

3.2. Giemsa C-Band Analyses of Chromosomes. Eight species, E. sagittatum, E. alpinum, E. pubigerum, E. acuminatum, E. simplicifolium, E. wushanense, E. letorrhizum, and E. davidii, were treated by chromosomes C-banding. The metaphase chromosomes of C-banding, Giemsa C-banding karyotypes and idiograms of C-banding karyotype can be seen in Figures 3,4 , and 5 , respectively.

Results showed that the chromosomes C-banding of eight species vary remarkably, with 15 to 22 bands, consisting of centromeric bands, intercalary bands, terminal bands, and middle satellite bands. Based on the number and location of the bands, the tested eight species can be divided into 


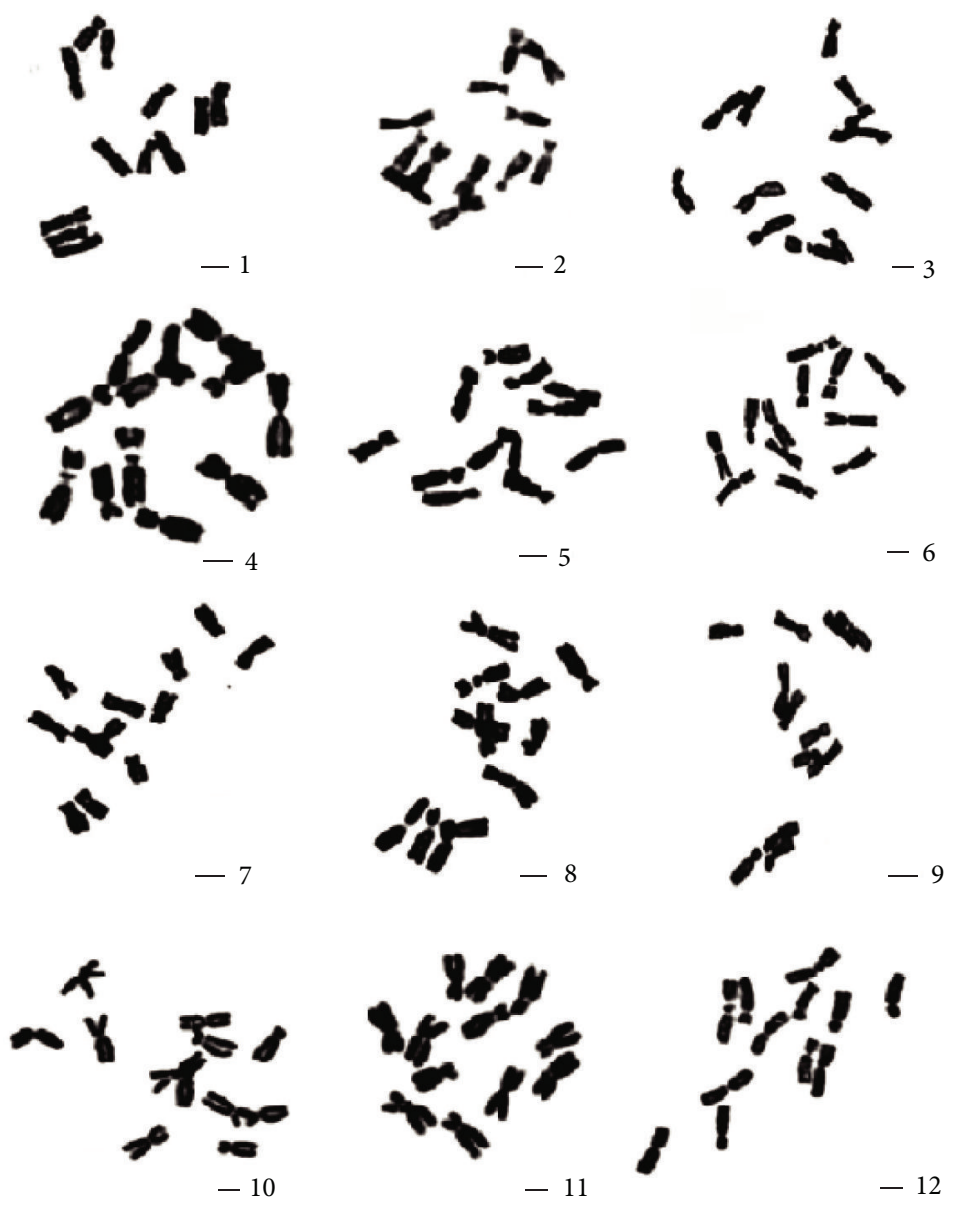

FIGURE 1: Somatic chromosome of Epimedium, all species with 2n = 12. 1-10: large-flower group. 1: E. acuminatum. 2: E. yinjiangense. 3: E. luodianense. 4: E. leptorrhizum. 5: E. simplicifolium. 6: E. wushanense. 7: E. alpinum. 8: E. davidii. 9: E. pubigerum. 10: E. franchetii. 11-12: small-flower group. 11: E. myrianthum. 12: E. sagittatum. Scale bar $=2 \mu \mathrm{m}$.

TABLE 2: Karyotype formula (KF), satellite position (SAT), total length of the haploid complement (TCL), range of chromosome length (range), intrachromosome asymmetry index $\left(A_{1}\right)$, interchromosome asymmetry $\left(A_{2}\right)$, mean centromeric index (CI), and Stebbin's asymmetry categories (ST) of the studied Epimedium species.

\begin{tabular}{|c|c|c|c|c|c|c|c|c|}
\hline Species & $\mathrm{KF}$ & SAT & $\mathrm{TCL} \pm \mathrm{SE}$ & Range & $A_{1}$ & $A_{2}$ & $\mathrm{CI} \pm \mathrm{SE}$ & ST \\
\hline E. acuminatum & $4 m+6 s m+2 m(S A T)$ & 1s & $45.23 \pm 0.78$ & $3.08 \sim 4.77$ & 0.38 & 0.17 & $37.54 \pm 0.15$ & $2 \mathrm{~A}$ \\
\hline E. yinjiangense & $4 \mathrm{~m}+6 \mathrm{sm}+2 \mathrm{~m}(\mathrm{SAT})^{*}$ & $1 \mathrm{~s}$ & $29.23 \pm 2.36$ & $2.15 \sim 2.92$ & 0.43 & 0.14 & $35.76 \pm 0.28$ & $2 \mathrm{~A}$ \\
\hline E. luodianense & $4 \mathrm{~m}+6 \mathrm{sm}+2 \mathrm{~m}(\mathrm{SAT})^{*}$ & $1 \mathrm{~s}$ & $47.88 \pm 1.24$ & $2.28 \sim 4.87$ & 0.38 & 0.17 & $36.69 \pm 0.31$ & $2 \mathrm{~A}$ \\
\hline E. leptorrhizum & $6 \mathrm{~m}+4 \mathrm{sm}+2 \mathrm{~m}(\mathrm{SAT})^{*}$ & $2 \mathrm{~s}$ & $46.00 \pm 1.04$ & $3.06 \sim 4.44$ & 0.34 & 0.14 & $39.00 \pm 0.14$ & $2 \mathrm{~A}$ \\
\hline E. simplicifoilum & $4 \mathrm{~m}+6 \mathrm{sm}+2 \mathrm{~m}(\mathrm{SAT})^{*}$ & $2 s$ & $45.43 \pm 2.01$ & $3.05 \sim 4.17$ & 0.42 & 0.11 & $36.06 \pm 0.52$ & $2 \mathrm{~A}$ \\
\hline E. wushanense & $4 \mathrm{~m}+6 \mathrm{sm}+2 \mathrm{~m}(\mathrm{SAT})^{*}$ & $2 s$ & $46.86 \pm 0.88$ & $3.33 \sim 4.44$ & 0.33 & 0.10 & $39.40 \pm 0.46$ & $2 \mathrm{~A}$ \\
\hline E. alpinum & $4 \mathrm{~m}+6 \mathrm{sm}+2 \mathrm{~m}(\mathrm{SAT})$ & $1 \mathrm{~s}$ & $32.96 \pm 1.34$ & $2.22 \sim 3.06$ & 0.35 & 0.13 & $38.39 \pm 0.39$ & $2 \mathrm{~A}$ \\
\hline E. davidii & $4 \mathrm{~m}+6 \mathrm{sm}+2 \mathrm{~m}(\mathrm{SAT})^{*}$ & $1 \mathrm{~s}$ & $47.32 \pm 1.67$ & $3.33 \sim 4.72$ & 0.42 & 0.16 & $36.08 \pm 0.22$ & $2 \mathrm{~A}$ \\
\hline E. pubigerum & $4 m+6 s m+2 m(S A T)$ & $1 \mathrm{~s}$ & $38.59 \pm 0.96$ & $2.50 \sim 3.61$ & 0.32 & 0.14 & $39.88 \pm 0.18$ & $2 \mathrm{~A}$ \\
\hline E. franchetii & $4 m+6 s m+2 m(S A T)^{*}$ & $1 \mathrm{~s}$ & $38.04 \pm 0.82$ & $2.91 \sim 4.72$ & 0.36 & 0.18 & $38.20 \pm 0.29$ & $2 \mathrm{~A}$ \\
\hline E. myrianthum & $4 \mathrm{~m}+6 \mathrm{sm}+2 \mathrm{~m}(\mathrm{SAT})^{*}$ & 1s & $45.45 \pm 1.27$ & $3.38 \sim 4.15$ & 0.40 & 0.08 & $36.69 \pm 0.38$ & $2 \mathrm{~A}$ \\
\hline E. sagittatum & $4 m+6 s m+2 m(S A T)$ & $1 \mathrm{~s}$ & $41.88 \pm 1.01$ & $3.27 \sim 4.68$ & 0.34 & 0.18 & $38.69 \pm 0.13$ & $2 \mathrm{~A}$ \\
\hline
\end{tabular}

SE: standard error, m: metacentric, sm: submetacentric, st: subteleocentric, s: short arm, and ${ }^{*}$ indicates first description of species. 


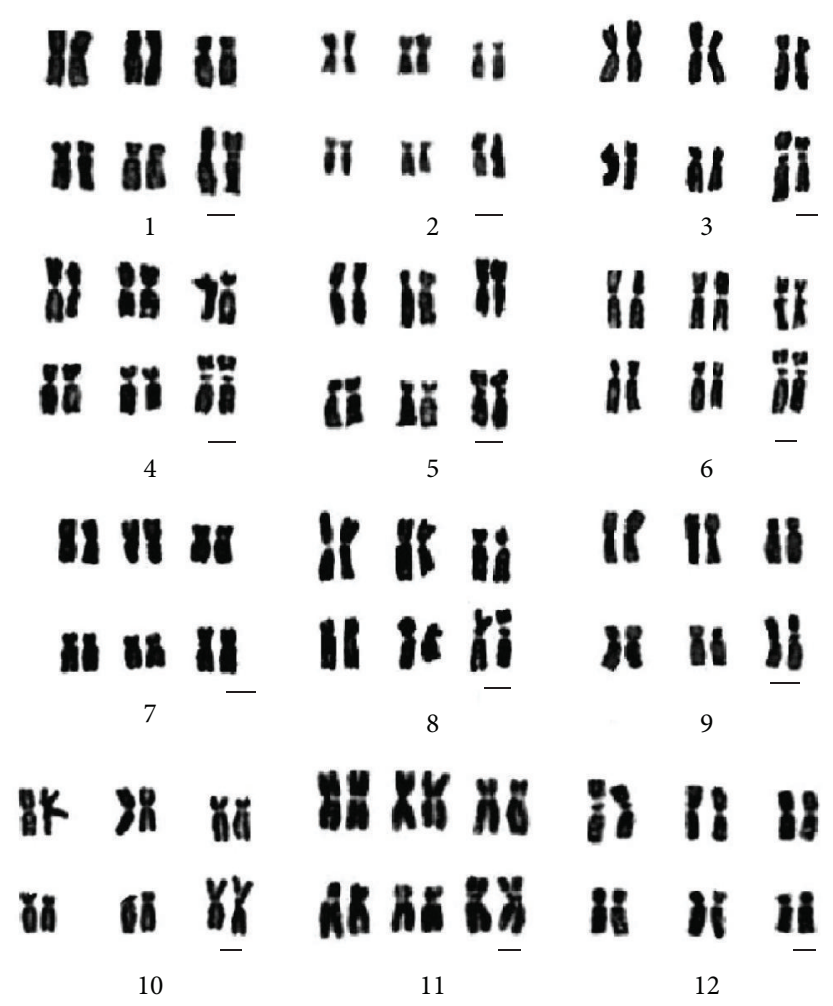

Figure 2: Karyotypes of twelve species metaphase chromosomes, all species with 2n = 12. 1-10: large-flower group. 1: E. acuminatum. 2: E. yinjiangense. 3: E. luodianense. 4: E. leptorrhizum. 5: E. simplicifolium. 6: E. wushanense. 7: E. alpinum. 8: E. davidii. 9: E. pubigerum. 10: E. franchetii. 11-12: small-flower group. 11: E. myrianthum. 12: E. sagittatum. Scale bar $=2 \mu \mathrm{m}$.

three groups: Group 1 comprises E. sagittatum, with only 15 C-bands; Group 2, E. alpinum and E. pubigerum native to Germany, with 18 C-bands; Group 3, E. acuminatum, E. simplicifolium, E. leptorrhizum, and E. davidii, with the Cband number from 20 to 22 .

3.3. Peroxide Isozyme. The results showed that the POD isozyme zymographs of various leaves of the same accession are similar. For accurate comparison among accessions, the zymographs of all accessions were prepared on a single biogel plate (Figure 6). Sixteen bands of POD isozyme (POD 1-16) were detected in the eleven species. Each species has its own characteristic bands, different from others, showing that the POD isozyme zymographs vary greatly among genus Epimedium. Among the eleven species, the zymograph bands of $E$. pubigerum were the most abundant, with eleven bands (POD1-3, POD 7, and POD 10-16), E. yinjiangense with only one band (POD 1), and E. luodianense with two bands (POD 1 and 5). All the zymographs can be divided into three regions, namely, slow $(R f \leqslant 0.20)$, medium $(0.2<R f \leqslant 0.60)$, and fast $(0.6<R f \leqslant 1.00)$.

The dissimilarity coefficient $(d)$ of isozyme zymograph is the symbol of relationships among species [27]. To find out the relationship of these species, the $d$ and $\bar{d}$ value of POD isozyme zymogram were studied and filled in Table 3 . The $d$ value of E. acuminatum and E. sagittatum is the lowest, 0.091, and E. franchetii and E. yinjiangense the highest, 1.00. The $\bar{d}$ values of E. franchetii, E. pubigerum, and E. yinjiangense are higher, respectively, $0.678,0.669$, and 0.621 . And the $\bar{d}$ values of E. sagittatum and E. myrianthum (small-flower), respectively, are 0.432 and 0.418 , lower than the others.

3.4. HPLC Fingerprint of Flavonoids. The flavonoids HPLC fingerprints of twenty-one barrenwort accessions, belonging to eight species were observed (Figure 7). The result showed that the HPLC fingerprint of different species were different. Each species had characteristic peaks, which were different from those seen in other species. All the HPLC fingerprint peaks can be divided into two regions: Region 1, retention time $<10 \mathrm{~min}$, and Region 2, retention time $>10 \mathrm{~min}$. Based on the number and location of peaks held by the species in Region 2, the eight species can be grouped into three types: Type 1 (E. sagittatum) with Peak 1-8, Type 2 (E. acuminatum, E. yinjiangense, E. wushanense, and E. simplicifolium) with Peak 1-5, and Type 3 (E. luodianense and E. leptorrhizum) without any peak, suggesting that the relation among $E$. acuminatum, E. yinjiangense, E. wushanense, E. simplicifolium, and E. davidii is near each other; E. luodianense and $E$. leptorrhizum are also near. E. sagittatum is distant from other species.

3.5. Interspecific Crossability. The crossabilities of fourteen accessions belonging to seven species were studied in the aspect of the grain set rate of hybridization (Table 4). Results 


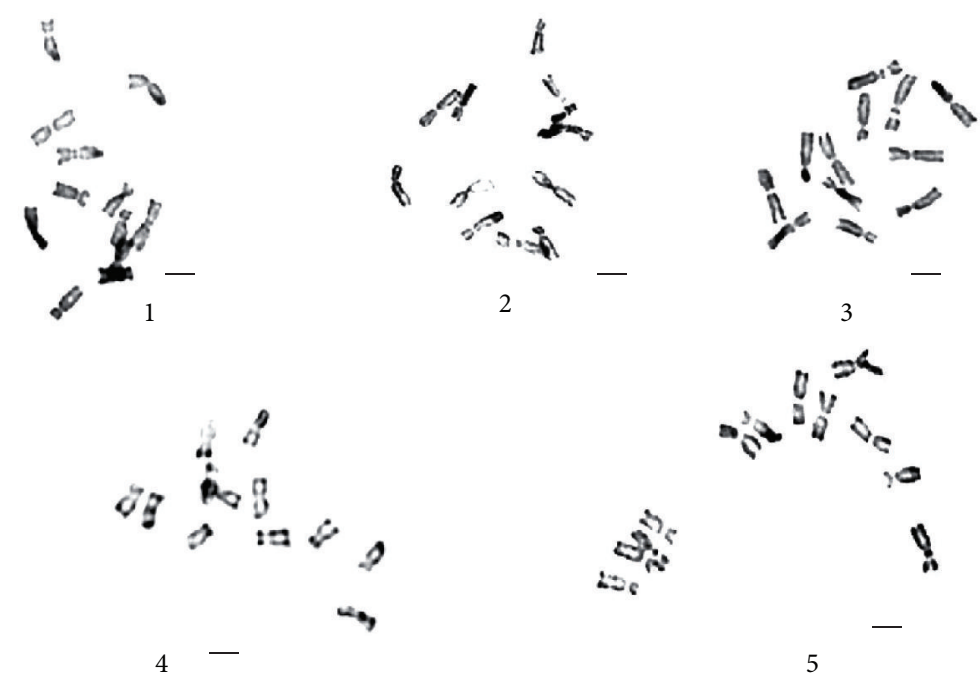

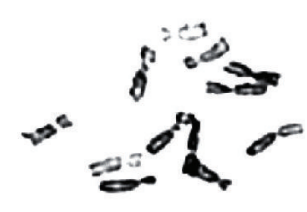

6

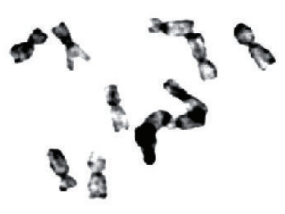

7

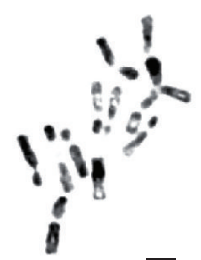

8

FIGURE 3: The metaphase chromosomes C, banding in the eight species of genus Epimedium. 1: E. simplicifolium. 2: E. leptorrhizum. 3: E. wushanense. 4: E. alpinum. 5: E. davidii. 6: E. acuminatum. 7: E. pubigerum. 8: E. sagittatum. Scale bar $=2 \mu \mathrm{m}$.

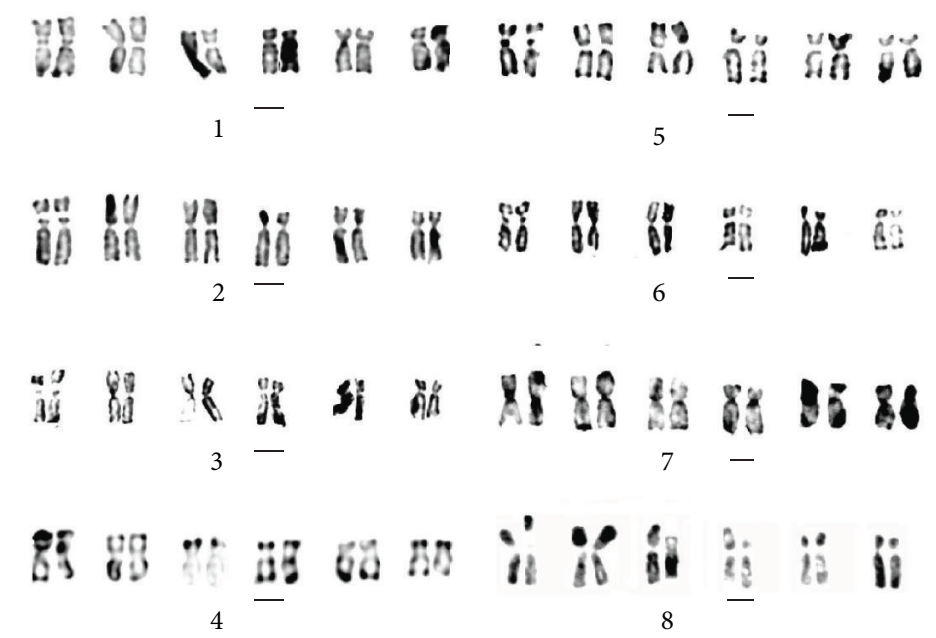

Figure 4: Giemsa C-banded karyotypes in the eight species of genus Epimedium. 1: E. simplicifolium. 2: E. leptorrhizum. 3: E. wushanense. 4: E. alpinum. 5: E. davidii. 6: E. acuminatum. 7: E. pubigerum. 8: E. sagittatum. Scale bar $=2 \mu \mathrm{m}$.

showed that the hybridizations of any combination among seven species are successful, and the rate of grain set among hybridization combinations vary obviously for the grain set rate of E. luodianense and E. letorrhizum is the highest (up to 92.44\%) and E. myrianthum and E. acuminatum the lowest (only $15.38 \%$ ). Based on the rates, seven species studied can be divided into two groups: Group one is only one species, $E$. myrianthum, with lower grain set rate of crossing with other species (almost all under 30\%); Group two is the rest, with higher grain set rate (almost all over 30\%). 


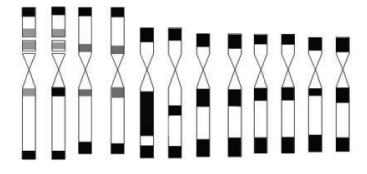

1

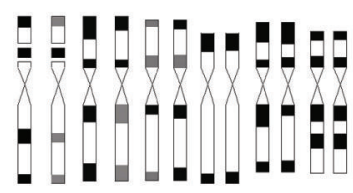

3
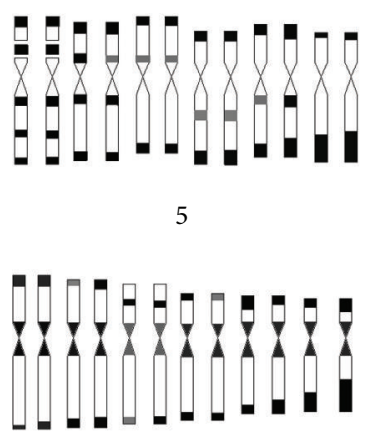
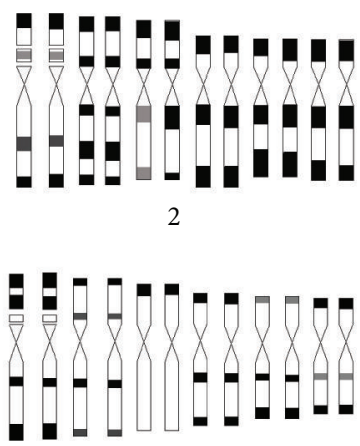

4

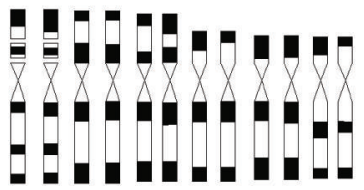

6

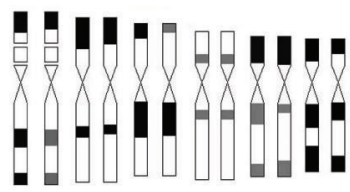

FIGURE 5: Idiograms of C-banded karyotypes in the eight species of genus Epimedium. 1: E. simplicifolium. 2: E. leptorrhizum. 3: E. wushanense. 4: E. alpinum. 5: E. davidii. 6: E. acuminatum. 7: E. pubigerum. 8: E. sagittatum.

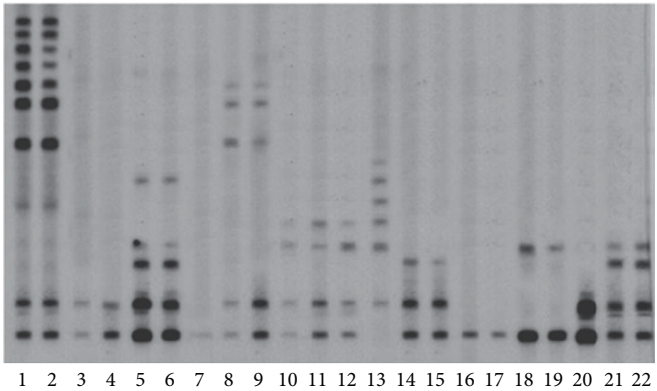

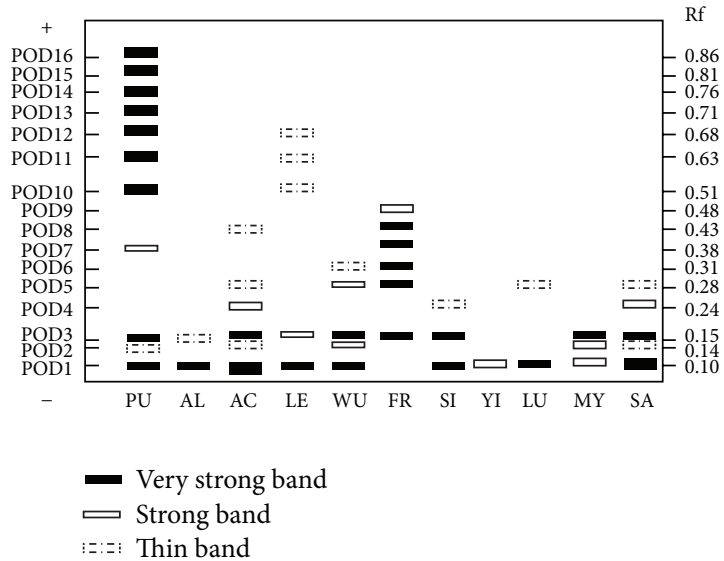

(b)

FIGURE 6: The POD isozyme zymogram and idiogram of twelve species of genus Epimedium. $1=\mathrm{PU} 1,2=\mathrm{PU} 2,3=\mathrm{AL1}, 4=\mathrm{AL} 2,5=\mathrm{AC} 37,6$ = AC22, 7 = LE10, 8 = LE5, $9=\mathrm{LE} 6,10=\mathrm{WU} 15,11=\mathrm{WU} 10,12=\mathrm{WU} 16,13=\mathrm{FR} 1,14=\mathrm{SI} 1,15=\mathrm{SI} 2,16=\mathrm{YI} 1,17=\mathrm{YI} 2,18=\mathrm{LU} 1,19=\mathrm{LU} 4,20$ $=\mathrm{MY} 1,21=\mathrm{SA} 1$, and $22=\mathrm{SA} 2$.

Results also showed that there are no various differences between the grain set rates of positive and negative hybridization, suggesting that the significance of grain set rats of positive and negative hybridization in symboling the interspecific relationship of this genus is the same. So the means of grain set rats of positive and negative hybridization were analyzed by the unweighted pair-group method (UPGMA) (Figure 8) to find the relationship of seven species researched in this paper. Results showed that E. myrianthum is very distant from other six species, and the relation between E. luodianense and E. yinjiangense is the nearest, and they are nearer related to $E$. letorrhizum. 


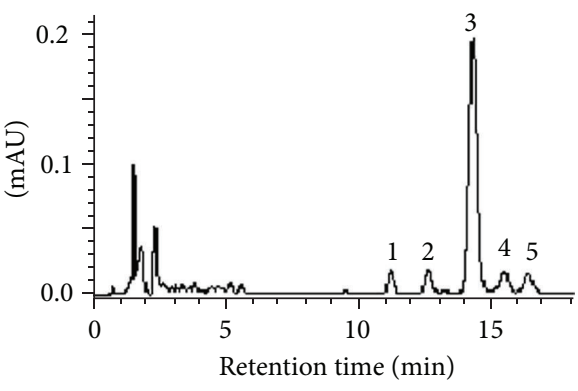

1

(a)

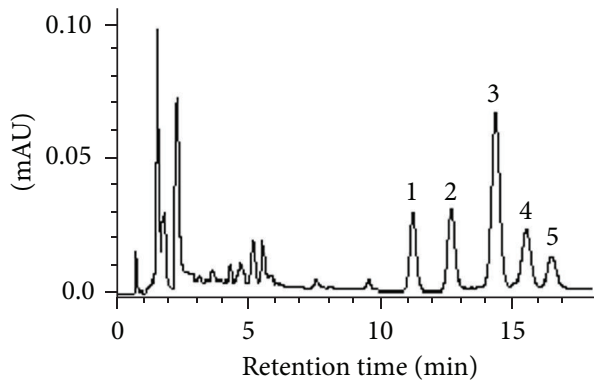

3

(c)

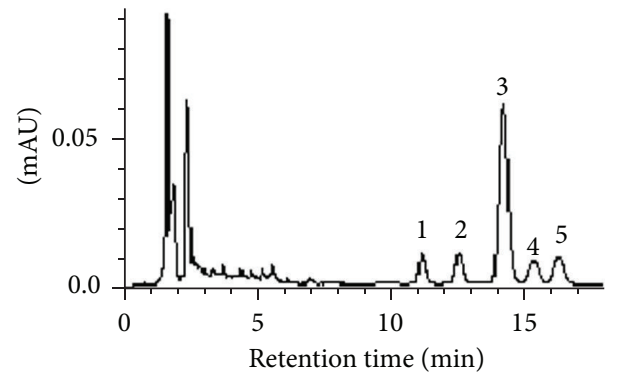

5

(e)

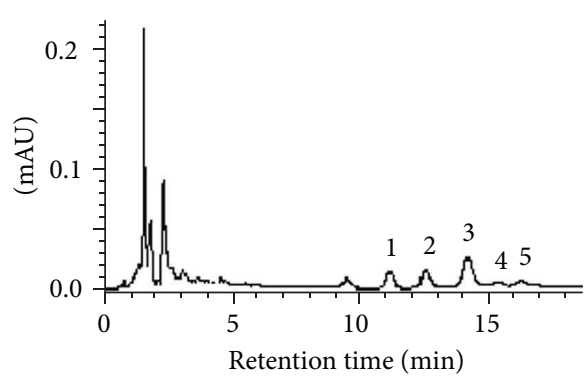

7

(g)

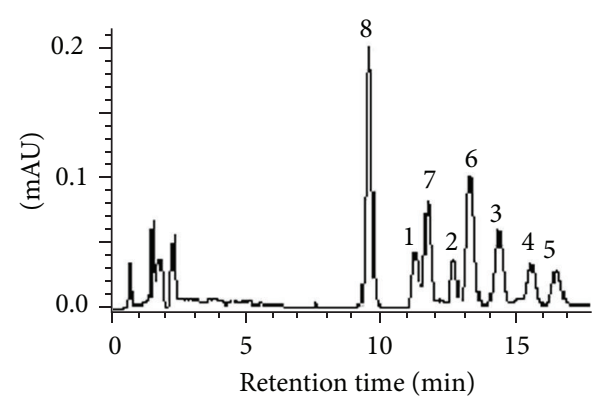

2

(b)

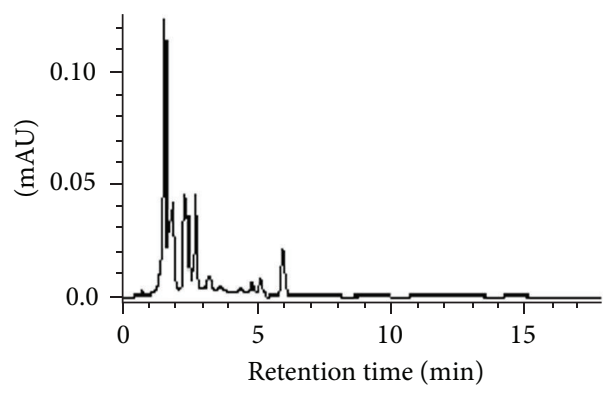

4

(d)

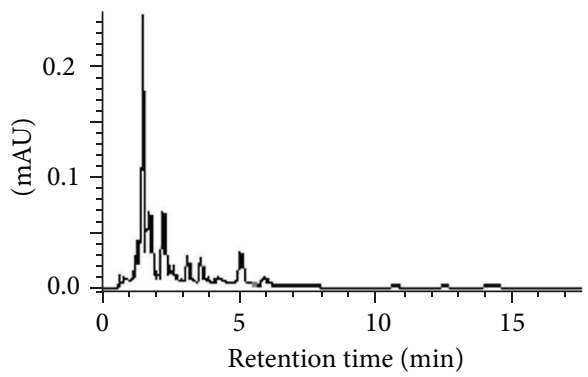

6

(f)

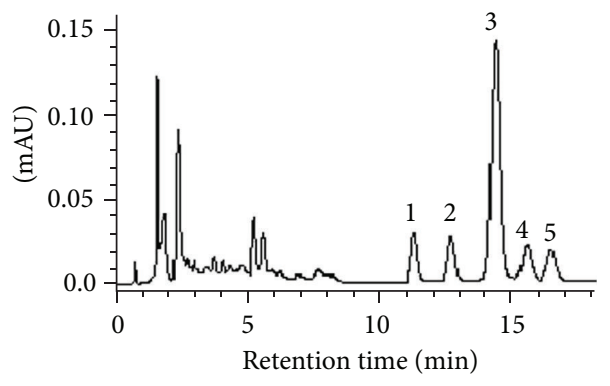

8

(h)

FIGURE 7: HPLC fingerprint of eight species. 1: E. wushanense. 2: E. sagittatum. 3: E. yinjiangense. 4: E. leptorrhizum. 5: E. simplicifolium. 6: E. luodianense. 7: E. davidii. 8: E. acuminatum. 
TABLE 3: The interspecific dissimilarity coefficient $(d, \%)$ of POD zymogram of eleven barrenwort species and their means.

\begin{tabular}{|c|c|c|c|c|c|c|c|c|c|c|c|c|}
\hline Species & FR & PU & YI & LE & LU & SI & $\mathrm{AC}$ & $\mathrm{AL}$ & WU & MY & SA & Mean $(\bar{d})$ \\
\hline FR & & & & & & & & & & & & 67.8 \\
\hline PU & 76.5 & & & & & & & & & & & 66.9 \\
\hline YI & 100 & 83.3 & & & & & & & & & & 62.1 \\
\hline LE & 81.8 & 37.5 & 66.7 & & & & & & & & & 58.4 \\
\hline LU & 75.0 & 86.4 & 33.3 & 71.4 & & & & & & & & 57.0 \\
\hline SI & 77.8 & 71.4 & 50.0 & 50.0 & 60.0 & & & & & & & 47.1 \\
\hline $\mathrm{AC}$ & 50.0 & 64.7 & 71.4 & 63.6 & 50.0 & 33.3 & & & & & & 45.3 \\
\hline $\mathrm{AL}$ & 75.0 & 69.2 & 33.3 & 42.9 & 50.0 & 20.0 & 50.0 & & & & & 44.6 \\
\hline WU & 45.5 & 62.5 & 66.7 & 60.0 & 42.9 & 50.0 & 27.2 & 42.9 & & & & 44.3 \\
\hline MY & 77.8 & 57.1 & 50.0 & 50.0 & 60.0 & 33.3 & 33.3 & 20.0 & 25.0 & & & 43.2 \\
\hline SA & 63.6 & 62.5 & 66.7 & 60.0 & 42.9 & 25.0 & 9.1 & 42.9 & 20.0 & 25.0 & & 41.8 \\
\hline Mean $(\bar{d})$ & 67.8 & 66.9 & 62.1 & 58.4 & 57.0 & 47.1 & 45.3 & 44.6 & 44.3 & 43.2 & 41.8 & 52.59 \\
\hline
\end{tabular}

TABLE 4: The rate of grain set (\%) of hybridization between species.

\begin{tabular}{|c|c|c|c|c|c|c|c|}
\hline \multirow{2}{*}{0} & \multicolumn{7}{|c|}{ 우 } \\
\hline & E. myrianthum & E. acuminatum & E. wushanense & E. letorrhizum & E. luodianense & E. simplicifolium & E. yinjiangense \\
\hline E. myrianthum & & 15.38 & 15.83 & 26.97 & 35.82 & 16.85 & 30.09 \\
\hline E. acuminatum & 29.17 & & 49.51 & 24.34 & 47.06 & 73.35 & 41.67 \\
\hline E. wushanense & 33.03 & 60.32 & & 28.26 & 63.41 & 92.23 & 64.04 \\
\hline E. letorrhizum & 28.69 & 29.62 & 42.86 & & 92.44 & 87.01 & 76.47 \\
\hline E. luodianense & 35.96 & 43.88 & 80.15 & 67.68 & & 73.08 & 88.07 \\
\hline E. simplicifolium & 35.05 & 71.43 & 88.78 & 75.00 & 48.20 & & 77.01 \\
\hline E. yinjiangense & 20.80 & 43.08 & 72.73 & 41.38 & 83.33 & 62.92 & \\
\hline
\end{tabular}

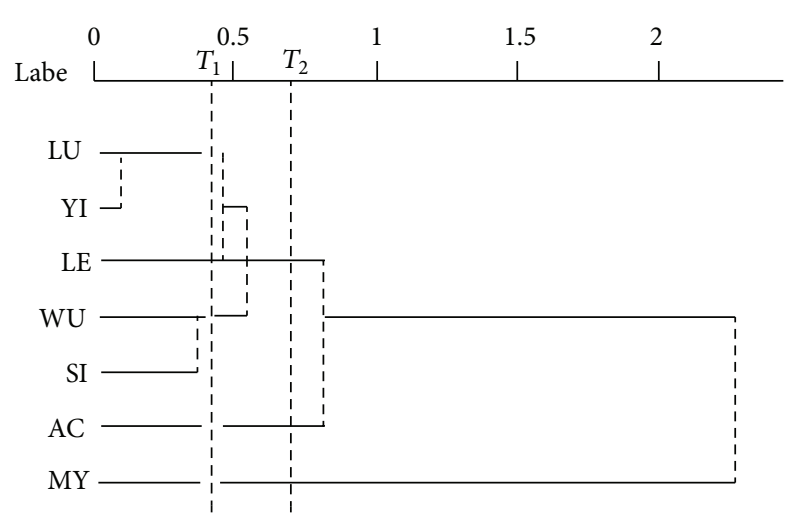

Figure 8: Clustering of seven species by the grain set rate of hybridization.

\section{Discussion}

4.1. Generic Evolution. The results showed that karyotypes of twelve species are 2A symmetry type of Stebbins [22] standard and similar to each other only with $\mathrm{m}$ and sm chromosomes, and interspecific hybridization easily succeeds, suggesting that Epimedium is a very conservative genus in the process of evolution.

The longer the evolutionary history, the larger the DNA differentiation and the higher the average value of zymogram distance [27]. Su and Liu [28] concluded that Dysosma is an age-old genus based on the average value of its isozyme zymogram distance, 0.828 . In our study, this value was 0.526 , indicating that Epimedium may be a more ancient genus in the family Berberidaceae. This result is consistent with those studies results of geobiology [6], pollen morphology [8], molecular biology [13-16], and cytology [23, 29] of this genus, also supported by the deduction about the phylogeny of Berberidaceae by Wu et al. [2].

Karyotype formulas of E. sagittatum, E. myrianthum, E. acuminatum, E. wushanense, E. simplicifolium, E, yinjiangense, E. luodianense, E. davidii, E. pubigerum, E. franchetii, and $E$. alpinum are $2 \mathrm{n}=2 \mathrm{x}=6 \mathrm{~m}(2 \mathrm{SAT})+6 \mathrm{sm}$, and $E$. leptorrhizum is $2 \mathrm{n}=2 \mathrm{x}=8 \mathrm{~m}(2 \mathrm{SAT})+4 \mathrm{sm}$. Karyotype formulas of four genus, Diphylleia, Dysasma, Podophyllum and Sinopodophyllum, of family Berberidaceae are $2 \mathrm{n}=2 \mathrm{x}=$ $8 \mathrm{~m}(\mathrm{SAT})+2 \mathrm{st}+2 \mathrm{t}, 2 \mathrm{n}=2 \mathrm{x}=8 \mathrm{~m}(2 \mathrm{SAT})+2 \mathrm{st}(\mathrm{SAT})+2 \mathrm{t}, 2 \mathrm{n}$ $=2 \mathrm{x}=6 \mathrm{~m}(4 \mathrm{SAT})+2 \mathrm{sm}+2 \mathrm{st}+2 \mathrm{t}$, and $2 \mathrm{n}=2 \mathrm{x}=8 \mathrm{~m}(2 \mathrm{SAT})$ +2 st $(2 \mathrm{SAT})+2 \mathrm{t}$, respectively $[23,29]$. Along with the level of evolution advancement, the asymmetry of karyotype will enhance in family Berberidaceae [29]. Obviously, the karyotypes of Epimedium are the most symmetrical among genus of Berberidaceae, suggesting that Epimedium is the most original genus in the family Berberidaceae.

4.2. Interspecific Relationship. Results of chromosomes Cbanding, POD isozyme, HPLC fingerprint, and interspecific hybridization researches all show that small-flower species, $E$. sagittatum and E. myrianthum, are distant from the ten large 
flower species, strongly supporting the flower size which is one of the important taxonomy symbols of this genus, and genus Epimedium should be classed into two sections: small and large flower.

In large flower species, the relation among $E$. leptorrhizum, E. luodianense, and E. jinjiangense is near based on results of POD isozyme, HPLC fingerprint, and the grain set rate of interspecific hybridization. Results of HPLC fingerprint that showed peaks in Region 2 of E. acuminatum, E. simplicifolium, E. wushanense, and E. davidii are the same with Peaks 1-5, suggesting that the relation of these four species are near, also supported by the result of interspecific hybridization research. Results of chromosomes C-banding showed that E. alpinum and E. pubigerum were divided into the same group, suggesting that the relation of these two species are near. Results of POD isozyme analyses showed that the zymograph of $E$. franchetii varies greatly from the others, suggesting that $E$. franchetii is distant from the rest.

Modernistic taxonomy sparkplug that species set by classical morphologic criteria should be classed into biological species renewedly. Results of interspecific hybridization among seven barrenwort species showed only E. myrianthum, with lower grain set rate of crossing with other species (almost all under 30\%), maybe a biological species. However, the others are not biological species for there are high grain set rate each other. There will be lots of works to do in studying biological species of this genus.

4.3. Origin of This Genus. The distribution pattern of Epimedium is the typical type of old world temperate zone [6], internationally distributing in three discontinuous areas of the Mediterranean Sea and Western Asia, China, and Japan. China is the diversity centre of this genus with about 50 species and five infraspecies on record [25], mostly occurring in the south-western China. However, studies on the origin of this genus still have not sure conclusions.

This study on POD isozyme showed that the means of $d$ values of the two species of the small-flowers group, $E$. sagittatum and E. myrianthum, were 0.432 and 0.418 , respectively, lower than the large-flowers group species, implying that the small-flowers group is older in genus Epimedium. It is possible that the course of evolution of Epimedium was from the small-flowers group to the large-flowers group. Since it is known that south-western China is the origin centre of the small-flowers group of this genus [6], south-western China may also be the origin centre of the genus Epimedium.

\section{Acknowledgments}

The authors are grateful to Chen Qing-Fu, Yang QingXiong, and Yang Zhen-Fu (Institute of Pant Genetics and Breeding, Guizhou Normal University) for their help and to the National Key Technology R\&D Program of China for the 12th Five-Year Plan (No. 2011BAC09B01), the Guizhou Normal University Fund for Doctor Research (no. 2012), and the Guizhou Project of Chinese Traditional Medicine Modernization (Qianke HeNong Zi (2005) no. 5052) for providing funds.

\section{References}

[1] L. Zhang, Y. Wang, and H. T. Mao, "Study on the inhibition of telomerase activity and regulated mechanism in human cancer cell by icarrin," Chinese Journal of Immunology, vol. 18, pp. 191196, 2002.

[2] Z. Y. Wu, L. U. AM, and Y. C. Tang, The Families and Genera of Angiosperms in China, Science Press, Beijing, China, 2003.

[3] J. P. Xie and W. J. Sun, "Progress of chemical materials and pharmacy of genus Epimedium plants," Strait Pharmaceutical Journal, vol. 18, pp. 17-20, 2006.

[4] B. L. Guo and P. G. Xiao, "The flavonoids in Epimedium L. and their taxonomic significance," Acta Phytotaxonomica Sinica, vol. 37, pp. 228-243, 1999.

[5] W. T. Stearn, The Genus Epimedium and Other Herbaceous Berberidaceae, Timber Press, Portland, Org, USA, 2002.

[6] T. S. Ying, "Petal evolution and distribution patterns of Epimedium L., (Berberidaceae)," Acta Phytotaxonomica Sinica, vol. 40, pp. 481-489, 2002.

[7] W. T. Stearn, "Epimedium and Vancouveria (Berberidacease), a monograph," Journal of the Linnean Society of London, Botany, vol. 51, no. 340, pp. 409-435, 1938.

[8] K. T. Zhang and P. L. Wang, "Study on the pollen morphology of the family Berberidaceae," Acta Phytotaxonomica Sinica, vol. 21, pp. 130-141, 1983.

[9] H. R. Liang and W. M. Yan, "Studies on the pollen morphology of Epimedium in China," Bulletin of Botanical Research, vol. 11, pp. 81-92, 1991.

[10] C. Takahashi, "Karyomorphological studies on speciation of Epimedium and its allied Vancouveria with special reference to C-bands," Journal of science of the Hiroshima University B, vol. 2, pp. 159-269, 1989.

[11] M. Y. Sheng and Q. F. Chen, "Karyotype analysis of six Epimedium species native to Guizhou, China," Guihaia, vol. 27, pp. 440-443, 2007.

[12] S. Koga, Y. Shoyama, and I. Nishioka, "Studies on Epimedium species: flavonol glycosides and isozymes," Biochemical Systematics and Ecology, vol. 19, no. 4, pp. 315-318, 1991.

[13] R. Nakai, Y. Shoyama, and S. Shiraishi, "Genetic characterization of Epimedium species using random amplified polymorphic DNA (RAPD) and PCR-restriction fragment length polymorphism (RFLP) diagnosis," Biological and Pharmaceutical Bulletin, vol. 19, no. 1, pp. 67-70, 1996.

[14] T. Wang, Y. J. Su, and J. M. Zhu, "RAPD analysis on some species of Berberidaceae," Bulletin of Botanical Research, vol. 21, pp. 428-431, 2001.

[15] Y. Sun, K. P. Fung, P. C. Leung, D. Shi, and P. C. Shaw, "Characterization of medicinal Epimedium species by $5 \mathrm{~S}$ rRNA gene spacer sequencing," Planta Medica, vol. 70, no. 3, pp. 287$288,2004$.

[16] Y. Sun, K. P. Fung, P. C. Leung, and P. C. Shaw, "A phylogenetic analysis of Epimedium (Berberidaceae) based on nuclear ribosomal DNA sequences," Molecular Phylogenetics and Evolution, vol. 35, no. 1, pp. 287-291, 2005.

[17] M. L. Zhang, C. H. Uhink, and J. W. Kadereit, "Phylogeny and biogeography of Epimedium/Vancouveria (Berberidaceae): Western North American-East Asian disjunctions, the origin of European mountain plant taxa, and East Asian species diversity," Systematic Botany, vol. 32, no. 1, pp. 81-92, 2007. 
[18] B. L. Guo, L. K. Pei, and P. G. Xiao, "Further research on taxonomic significance of flavonoids in Epimedium (Berberidaceae)," Journal of Systematics and Evolution, vol. 46, no. 6, pp. 874-885, 2008.

[19] Y. D. Kim, S. H. Kim, C. H. Kim, and R. K. Jansen, "Phylogeny of Berberidaceae based on sequences of the chloroplast gene ndhF", Biochemical Systematics and Ecology, vol. 32, no. 3, pp. 291-301, 2004.

[20] M. Y. Sheng, Q. F. Chen, and Q. X. Yang, "Variation in icariin and flavonoid contents of barrenwort accessions native to Guizhou, China," Biochemical Systematics and Ecology, vol. 36, no. 9, pp. 719-723, 2008.

[21] A. Levan, K. Fredga, and A. A. Sandberg, "Nomenclature for centromeric position on chromosomes," Heredity, vol. 52, pp. 201-220, 1964.

[22] Q. L. Stebbins, Chromosomal Evolution in Higher Plant, Edward Arnold, London, UK, 1971.

[23] L. C. Li, "A study on the karyotypes and evolution of dysosma pleiantha with its relatives," Acta Botanica Yunnanica, vol. 8, pp. 451-457, 1986.

[24] N. S. Hu and G. X. Wang, Isozyme Technology and Its Application, Hunan Scientific and Technological Publisher, Changsha, China, 1985.

[25] Committee of China Pharmacopoeia, China Pharmacopoeia, Chemical Industry Press, Beijing, China, 2005.

[26] R. Q. Du, Biostatistics, Higher Education Press and Springer, Beijing, China, 1999.

[27] Z. A. Hu, H. X. Wang, and L. F. Yan, "Biochemical systematics of gymnosperms (I) peroxidases of pinaceae," Acta Phytotaxonomica Sinica, vol. 21, no. 4, pp. 423-432, 1983.

[28] Y. J. Su and Q. H. Liu, "The POD analysis of dysosma native to Hubei," Journal of Wuhan Botanical Research, vol. 12, pp. 44-47, 1994.

[29] S. B. Ma and Z. H. Hu, "A karyotypic study on podophylloideae (Berberidaceae)," Acta Botanica Yunnanica, vol. 18, pp. 325-330, 1996. 

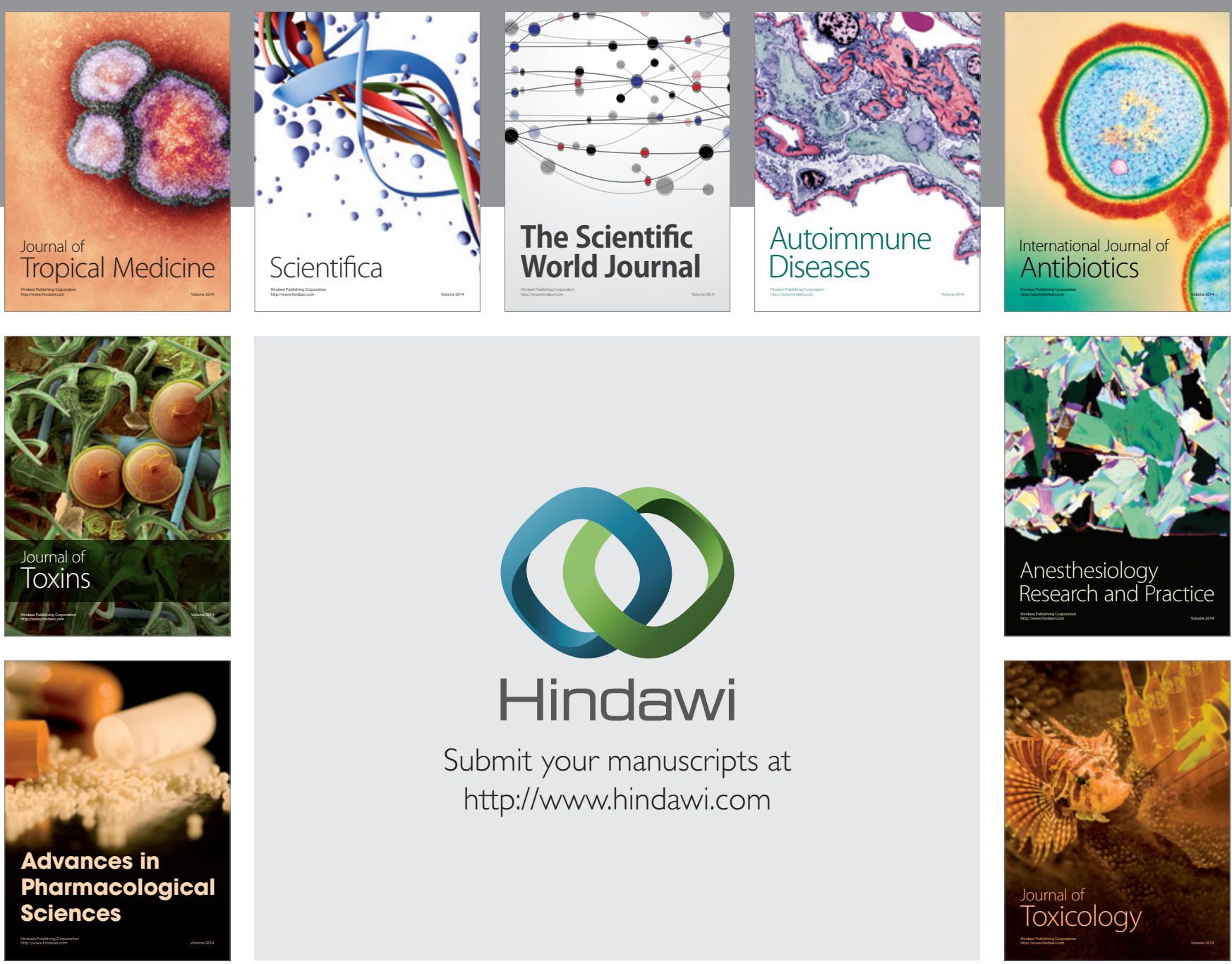

\section{Hindawi}

Submit your manuscripts at

http://www.hindawi.com
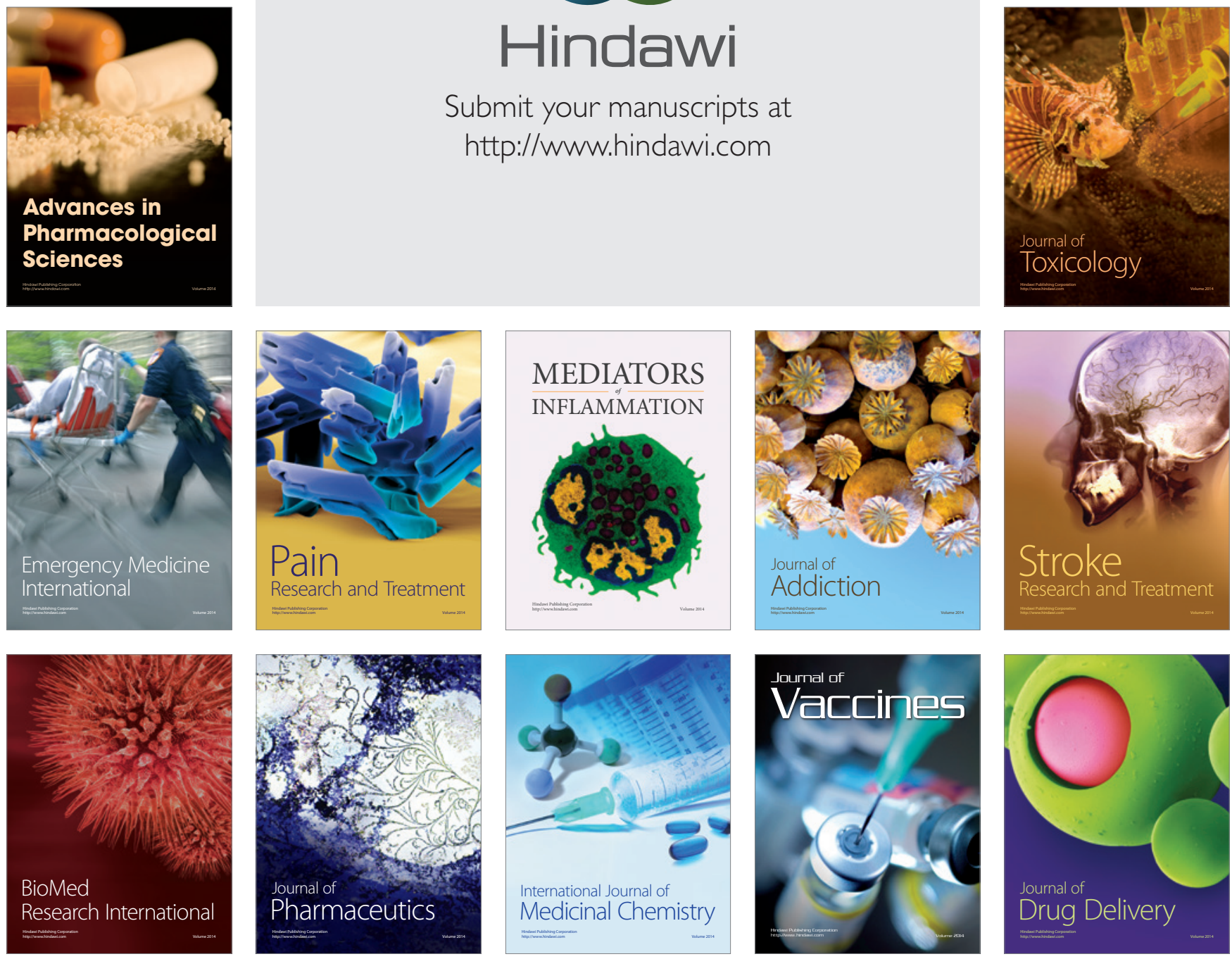